Département de sciences économiques

Cahier 2000-06

\title{
International Transmission of the Business Cycle in a Multi-Sector Model
}

AMBLER, Steve

CARDIA, Emanuela

ZIMMERMANN, Christian 


\section{Département de sciences économiques}

Université de Montréal

Faculté des arts et des sciences

C.P. 6128, succursale Centre-Ville

Montréal (Québec) H3C 3J7

Canada

http://www.sceco.umontreal.ca

SCECO-information@UMontreal.CA

Téléphone : (514) 343-6539

Télécopieur : (514) 343-7221

Ce cahier a également été publié par le Centre interuniversitaire de recherche en économie quantitative (CIREQ) sous le numéro 07-2000.

This working paper was also published by the Center for Interuniversity Research in Quantitative Economics (CIREQ), under number 07-2000.

ISSN 0709-9231 
CAHIER 2000-07

\section{INTERNATIONAL TRANSMISSION OF THE BUSINESS CYCLE IN A MULTI-SECTOR MODEL}

Steve AMBLER ${ }^{1}$, Emanuela CARDIA ${ }^{2}$ and Christian ZIMMERMANN ${ }^{1}$

1 Centre de recherche sur l'emploi et les fluctuations économiques (CREFÉ), Université du Québec à Montréal

2 Centre de recherche et développement en économique (C.R.D.E.) and Département de sciences économiques, Université de Montréal

April 2000

The authors would like to thank Brian Copeland, Martin Boileau, and participants at the Canadian Macro Study Group and the Society for Economic Dynamics and Control meetings for helpful discussions and comments on previous versions of this paper, and the Fonds pour la Formation de chercheurs et l'aide à la recherche (FCAR) of Québec for financial support. The usual caveat applies. 


\section{RÉSUMÉ}

Les modèles multi-pays n'ont pas réussi à reproduire des aspects importants de la transmission internationale des cycles économiques. Les modèles standards prédisent des corrélations inter-pays de l'output et de la consommation qui sont respectivement trop faibles et trop élevées. Dans cet article, nous construisons un modèle multi-pays de cycle économique avec des secteurs multiples afin d'analyser le rôle des chocs sectoriels dans la transmission internationale du cycle économique. Nous trouvons qu'un modèle avec des secteurs multiples génère une corrélation inter-pays de l'output plus élevée que les modèles standards à un secteur et une corrélation inter-pays de la consommation plus faible. De plus, il prédit des corrélations inter-pays de l'emploi et de l'investissement qui sont plus proches des données que le modèle standard. Nous analysons également les effets relatifs des secteurs multiples, du commerce des biens intermédiaires, de la substitution entre les biens domestiques et étrangers, de la préférence locale, des coûts d'ajustement du capital et de la dépréciation du capital sur la transmission internationale du cycle économique.

Mots clés : macroéconomie d'économie ouverte, cycles économiques, chocs sectoriels

\section{ABSTRACT}

Multi-country models have not been very successful in replicating important features of the international transmission of business cycles. Standard models predict crosscountry correlations of output and consumption which are respectively too low and too high. In this paper, we build a multi-country model of the business cycle with multiple sectors in order to analyze the role of sectoral shocks in the international transmission of the business cycle. We find that a model with multiple sectors generates a higher crosscountry correlation of output than standard one-sector models, and a lower cross-country correlation of consumption. In addition, it predicts cross-country correlations of employment and investment that are closer to the data than the standard model. We also analyze the relative effects of multiple sectors, trade in intermediate goods, imperfect substitution between domestic and foreign goods, home preference, capital adjustment costs, and capital depreciation on the international transmission of the business cycle.

Key words : open economy macroeconomics, business cycles, sectoral shocks 


\section{Introduction}

Dynamic general equilibrium models have been quite successful in replicating a large number of the stylized facts of the business cycle. However, multi-country models have done less well in replicating the stylized facts of the international transmission of the cycle. In a recent survey article, Backus, Kehoe and Kydland (1995, henceforth BKK) discuss two main puzzling features of the data that are hard for general equilibrium models to capture. ${ }^{1}$

First, there is what BKK refer to as a quantity anomaly. In the data, cross-country correlations of output are generally higher than cross-country correlations of aggregate productivity (as measured by Solow residuals), and the latter are generally higher than cross-country correlations of consumption (see Table 3 below). In addition, cross-country correlations of consumption and investment are generally positive in the data. In standard models, the ordering of the output, Solow residual and consumption correlations is reversed. Risk sharing between agents in different countries leads to high cross-country correlations of aggregate consumption. Incentives to use inputs where they are most productive often lead to negative cross-country correlations of output and especially of investment and employment.

Second, there is a price anomaly. General equilibrium models do not generate fluctuations in the terms of trade as large as those observed in the data. Models which restrict the elasticity of substitution between domestic and foreign goods can generate volatile terms of trade, but at the cost of a counterfactually low volatility of fluctuations in trade balances.

This paper is a contribution to the literature on explaining the quantity anomaly. We modify the supply side of the standard multi-country business cycle model by introducing multiple sectors and traded intermediate inputs. The main motivation for this change is the study by Long and Plosser (1983), one of the seminal contributions to the literature on real business cycle (RBC) models. They show that uncorrelated

\footnotetext{
${ }^{1}$ See also Ambler and Cardia (1995) on the cross-country correlations of macroeconomic aggregates and Baxter (1995) for a broad survey of international business cycle models.
} 
sectoral shocks in a dynamic closed-economy model can lead to positive spillover effects in other sectors via changes in demand for intermediate inputs produced by those sectors. A positive inter-sectoral transmission of productivity shocks in a closed-economy model could lead to a positive international transmission of sectoral shocks in a multi-country model.

We find that the introduction of multiple sectors brings the predictions of the model closer to what is observed in the data. Comparing the predictions of our multi-sector model with those of a standard onesector model yields the following results. The multi-sector model predicts a higher cross-country correlation of output than the one-sector model, and it predicts a slightly lower cross-correlation of consumption. The multi-sector model also predicts cross-country correlations of investment and employment that are significantly less negative than the one-sector model.

The paper is structured as follows. In the next section, we briefly review the stylized facts of the international transmission of the business cycle, we survey some recent papers that have attempted to explain the quantity anomaly, and we describe how our model differs from others in the literature. In the third section, we present our model and describe how to calculate its competitive equilibrium as the solution to a suitable social planning problem. In the fourth section, we discuss the model's steady state properties and its calibration. In the fifth section, we present the results from numerical simulations of a two-country

two-sector version of our model. We consider results for a base-case calibration and report the results of sensitivity analyses. We present our conclusions in the sixth section.

\section{Stylized Facts and Relevant Literature}

\subsection{The Facts}

Tables 2 and 3 contain rows which illustrate the stylized facts of the international transmission of the business cycle. The first row of both tables reports results for U.S. data (the data are described in detail in BKK). 
The cross-country averages in the second row of both tables are based on data from Zimmermann (1995). Zimmermann uses quarterly data from 19 industrialized countries from 1960:1 to 1991:2. Table 2 deals with comovements within individual countries. Aside from the real exchange rate (terms of trade) and the trade balance, these stylized facts are well known from the closed-economy business cycle literature, and are similar across industrialized countries. Consumption and employment are less volatile than output, investment is more volatile than output, and aggregates are highly correlated with output, except for the trade balance. In the case of the terms of trade and the trade balance, the U.S. data are less representative. The terms of trade are more volatile than GNP for all countries in the sample, but the contemporaneous correlations between the terms of trade and GNP and between the trade balance and GNP vary quite a bit over the sample. Figure 1 shows histograms for these two statistics for the countries in Zimmermann's sample.

Table 3 reports statistics which are more closely related to the international transmission of the cycle. The cross-country correlations in the first row of the table are between U.S. aggregates and the corresponding aggregate in a group of European countries. The cross-country correlation of consumption is lower than the cross-country correlation of output. The cross-country correlation of investment is slightly higher than the cross-country correlation of consumption, and the cross-country correlation of employment is significantly positive.

The cross-country averages calculated by Zimmermann (1995) and reported in the second row of Table 3 supports the quantity anomaly, in spite of the fact that the average cross correlations are lower than for the U.S. In Figure 2 we explore the data in more detail by reporting histograms for the cross-country contemporaneous correlations of different aggregates. The figure shows that the mean values reported in the second column of Table 3 mask a significant amount of variation across the countries in the sample. The ordering implicit in the quantity anomaly is not respected for all countries in the sample. Looking at pairwise contemporaneous cross correlations, the correlation between consumption levels is higher than the 
correlation between output levels in $30 \%$ of all possible cases. Comparing the highest cross correlations within leads or lags of up to fifteen quarters, the cross correlation of consumption is higher than that of output in $50 \%$ of all possible cases. The contemporaneous cross correlations of Solow residuals are higher than the contemporaneous cross correlations of output in $19 \%$ of possible cases, implying a negative international transmission of technology shocks. The data indicate that the quantity anomaly is not as strong as implied by the U.S. data alone.

\subsection{Recent Literature}

Several recent studies attempt to build models compatible with these features of the data. Some proceed by modifying the constraints on trades among agents. Kollmann (1992), Baxter and Crucini (1995), Heathcote and Perri (1997) and Arvanitis and Mikkola (1996) build models with incomplete asset markets which reduce the incentive for risk sharing. These authors find that incomplete markets help reduce the cross-country correlation of consumption, but the cross-country correlations of output, investment and hours worked remain counterfactually negative. Kehoe and Perri (1996) build a model in which international loans are not perfectly enforceable, so that the degree of market incompleteness is endogenous. Their model generates positive cross-country comovements of output, investment and employment. Ricketts and McCurdy (1995) build a two-country model with money and differing rates of trend productivity growth across countries. In the version of their model in which there is no international trade in investment goods, so that investment goods in a given country must be produced in the same country, they obtain a relative ordering of the cross-country correlations that is compatible with the data.

Other studies modify the specification of agents' preferences. Devereux, Gregory and Smith (1992) develop a model with a particular type of nonseparability between consumption and leisure. They succeed in lowering the cross-country correlation of consumption. Stockman and Tesar (1995) introducea nontraded goods sector in each country. They succeed in lowering the cross-country correlation of consumption while 
raising the cross-country correlation of output, but they do not consider the cross-country correlations of investment or hours worked. They also introduce taste shocks that displace preferences between traded and nontraded goods in order to increase the predicted variability of both the terms of trade and the trade balance. The quantity anomaly remains for the traded goods sectors. Finally, Canova and Ubide (1998) develop a two-country model with home production. Their results indicate that their model can generate cross-country correlations of output similar to those of consumption, and that it can generate positive crosscountry correlations of investment and employment.

Several papers in the literature build closed-economy business cycle models with multiple sectors. Long and Plosser (1983) is an early example. They analyze a multi-sector model of a closed economy which matches the input-output structure of the U.S. economy at a coarse level of disaggregation. They show that uncorrelated sectoral productivity shocks can lead to positive comovements in output across sectors. Hornstein and Praschnick (1997) distinguish between an intermediate and a final goods sector and show that sectoral productivity shocks can lead to positive comovements in output across sectors. Horvath (1998) builds a highly disaggregated multi-sector model of a closed economy.

Very few papers have included multiple sectors in a two-country model to examine the quantity anomalies discussed by BKK. Costello and Praschnick (1993) develop a two-country model which disaggregates each economy into one sector which produces an intermediate good and a single final goods sector. The final goods in the two countries are perfect substitutes. With complete markets and separability between leisure and consumption in the utility function, consumption is perfectly correlated across the two countries. Their model predicts a higher cross correlation of output than the BKK model. The paper does not examine the crosscountry correlations of investment and employment, which are important aspects of the quantity anomaly documented in BKK. Head (1997) builds a two-country model with differentiated intermediate goods and monopolistic competition. He shows that increasing returns to the variety of intermediate goods can lead to a 
positive international transmission of the business cycle. Kouparitsas (1996) builds a two-country model with a primary goods sector (whose output is used as an intermediate input in manufacturing), a manufacturing sector whose output is traded, and a nontradable services sector to examine the implications of increasing North-South trade in financial assets. Park (1998) builds a model with tradable and nontradable investment and consumption goods. His model generates positive cross-country correlation of aggregate output and a cross-country correlation of consumption which is lower than that of output.

Our model differs from previous studies in several respects. First, we analyze the implications of our model for all of the aggregates that characterize the quantity anomaly (output, consumption, employment, and investment). Second, our model assumes imperfect substitution between domestic and foreign output of all sectors. This means that there is cross-hauling (simultaneous exports and imports of goods of the same type) in all sectors. In the data, there is cross-hauling at fine levels of disaggregation in almost all sectors. $^{2}$ Third, our specification nests standard international business cycle models such as the one used by BKK. ${ }^{3}$ This allows us to analyze the impact of multiple sectors on the international transmission of the business cycle relative to other changes in specification, such as the degree of substitution between domestic and foreign output, trade in intermediate goods, capital adjustment costs, etc.

\section{The Model}

There are two countries with two sectors in each economy. The output of a given sector in a given country is an imperfect substitute for the outputs of the corresponding sectors in other countries, so that in equilibrium each country will produce some of each good. We use Armington (1969) aggregators to amalgamate domestic and foreign production of a given type of good. Then, the composite intermediate good from each sector can

\footnotetext{
${ }^{2}$ In our view, this makes the distinction between tradable and nontradable goods arbitrary and difficult to calibrate from the data.

${ }^{3}$ The nesting is not perfect, since we use capital adjustment costs rather than time-to-build as in BKK. We discuss this further below.
} 
be used as an input in any of the sectors of the economy, or it can enter a final production stage in which goods of different types are aggregated to form a final composite good, which is either consumed or invested to form capital. Output is perishable if used for consumption or as an intermediate input, and durable if used for investment. This structure is similar to that used in one-sector models, and is appropriate for the limited degree of disaggregation that we use in our model. The structure of the production side of the economy is summarized in Figure 3 below. ${ }^{4}$

Since there is one composite final good in each country, the model uses a standard specification of agents' preferences. ${ }^{5}$ There are no restrictions on trade in our model, and asset markets are complete, in contrast to some previous papers that have attempted to explain the quantity anomaly. Since markets are complete, competitive equilibrium is equivalent to an appropriately-defined social planning problem. This is in fact how we calculate the equilibrium allocations in our simulations. However, for the purposes of calibrating the model using its steady state properties we present and discuss the objectives and constraints of different types of economic agents in the model. Firms produce outputs by purchasing labor services and intermediate inputs and by renting capital from households. Infinitely-lived households supply labor and capital to firms and solve intertemporal maximization problems. Import brokers whose production functions are Armington aggregators amalgamate domestic and foreign output of a given type of good. Final goods brokers use CES aggregators to produce one homogeneous final good per country, which is purchased by households and used for consumption and investment.

\footnotetext{
${ }^{4}$ Thanks to Martin Boileau for providing the first draft of this figure.

${ }^{5}$ The Armington aggregator and the final goods aggregators could easily be reinterpreted as reflecting preferences for a variety of different goods. This would not change our results concerning the international transmission of shocks.
} 


\subsection{Firms}

The sectoral production functions are Cobb-Douglas ${ }^{6}$ and are given by

$$
Y_{p s t}=z_{p s t} N_{p s t}^{\alpha_{s}} K_{p s t}^{\gamma_{s}} \prod_{m=1}^{2} M_{p s m t}^{\zeta_{s m}}
$$

with

$$
\alpha_{s}+\gamma_{s}+\sum_{m=1}^{2} \zeta_{s m}=1
$$

so that there are constant returns to scale. The $p$ subscripts refer to the country where production takes place and the $s$ subscripts to the sector or type of good that is being produced. $M$ refers to the quantity of an intermediate good used in the production of good $s$. The order of the second and third subscripts in $M$ is important. The second subscript indicates the sector where the intermediate input is used (in this case sector $s$ ) and the third subscript indicates the sector where the intermediate input is produced (in this case $m$ ). There are two types of intermediate goods. $Y$ is output, $z$ is an exogenous productivity level, $N$ denotes hours worked, and $K$ is the stock of capital. The coefficients in the production processes do not have country-specific subscripts: apart from temporary divergences across countries of the $z$ 's, all countries have access to the same techniques of production. All quantities are measured in per capita terms.

Firms solve the static problem

$$
\max P_{p s t} Y_{p s t}-w_{p t} N_{p s t}-\left(r_{p s t}+\delta\right) K_{p s t}-\sum_{m=1}^{2} P_{p m t} M_{p s m t},
$$

where $P_{p s}$ gives the relative price of the output of the $s^{t h}$ sector of country $p$ measured in units of aggregate consumption. In the absence of transport costs, arbitrage will insure that this price is the same in all countries. Since labor is mobile across sectors, the real wage rate $w_{p t}$ is common to all sectors. In contrast, since capital cannot be transferred across sectors within the period, $r_{p s t}$, the rental rate net of depreciation costs in sector $s$, can be different across sectors in the short run (but not in the steady state).

\footnotetext{
${ }^{6}$ We also present results from a specification with a CES production function
} 


\subsection{Import Brokers}

The Armington aggregators are given by

$$
F_{u s t}=\phi_{u s}\left(X_{1 s u t}, X_{2 s u t}\right)=\left[\sum_{p=1}^{2} \omega_{p s u} X_{p s u t}^{\left(1-\rho_{s u}\right)}\right]^{\frac{1}{1-\rho_{s u}}},
$$

where $F_{u s t}$ is the quantity of good $s$ used in country $u$ for all purposes, and $X_{p s u t}$ is the quantity of good $s$ produced in country $p$ and used in country $u$. The value of $\omega_{p s u}$ can be set to impose home-country preference and symmetry across countries. The parameter $1 / \rho_{u s}$ is the elasticity of substitution between any of the $s$ goods produced in country $p=1,2$ and used by country $u$. With $\rho_{u s}$ close to zero the products are close to perfect substitutes. The following resource constraints for good $s$ produced by country $p$ and used by countries $u=1,2$, must hold:

$$
\sum_{u=1}^{2} \pi_{u} X_{p s u t}=\pi_{p} Y_{p s t}, \forall t,
$$

where $\pi_{u}$ is the population of country $u$ which uses good $s$ produced in country $p$ and $\pi_{p}$ is the population of country $p$ which produces good $s$.

The representative import broker for sector $s$ in country $u$ solves the static problem

$$
\max V_{u s t}\left[\sum_{p=1}^{2} \omega_{p s u} X_{p s u t}^{\left(1-\rho_{s u}\right)}\right]^{\frac{1}{1-\rho_{s u}}}-\sum_{p=1}^{2} P_{p s t} X_{p s u t},
$$

where $V_{u s t}$ is used to denote the relative price of composite good $s$ in country $u$.

\subsection{Domestic Brokers}

Domestic brokers buy composite goods from the different sectors and aggregate them together to produce one final good which is used by households for the purposes of consumption and investment. The final goods aggregators for each country are given by

$$
Y_{u t}=\psi_{u}\left(Q_{u 1 t}, Q_{u 2 t}\right)=\left[\sum_{s=1}^{2} \varpi_{u s} Q_{u s t}^{\left(1-\lambda_{u}\right)}\right]^{\frac{1}{1-\lambda_{u}}},
$$


where

$$
Q_{u s t} \equiv F_{u s t}-\sum_{m=1}^{2} M_{u m s t} .
$$

so that the amount of good $F_{\text {ust }}$ not used as intermediate inputs becomes an input into the aggregator function which yields the final good $Y_{u t}$.

Domestic brokers maximize domestic value added by solving the static profit maximization problem

$$
\max \left[\sum_{s=1}^{2} \varpi_{u s} Q_{u s t}^{\left(1-\lambda_{u}\right)}\right]^{\frac{1}{1-\lambda_{u}}}-\sum_{s=1}^{2} V_{u s t} Q_{u s t} .
$$

\subsection{Households}

Households are the only agents who must solve an intertemporal maximization problem. The representative household in country $u$ has an infinite planning horizon and its utility function is given by

$$
\begin{gathered}
U_{u t}=E_{t} \sum_{j=1}^{\infty} \beta^{j} u\left(C_{u, t+j}, 1-N_{u, t+j}\right) \\
=\frac{1}{1-\varepsilon_{u}} E_{t} \sum_{j=1}^{\infty} \beta^{j}\left[C_{u, t+j}^{\mu_{u}}\left(1-N_{u, t+j}\right)^{\left(1-\mu_{u}\right)}\right]^{1-\varepsilon_{u}},
\end{gathered}
$$

where $C_{u t}$ is consumption of the homogeneous final good, with $0<\mu_{u}<1,1-\varepsilon<1$ and where

$$
N_{u t}=\sum_{s=1}^{S} N_{u s t}
$$

The maximization problem for the representative household of country $u$ can be written as

$$
\max \frac{1}{1-\varepsilon_{u}} E_{t}\left(\sum_{j=0}^{\infty} \beta^{j}\left[C_{u, t+j}^{\mu_{u}}\left(1-N_{u, t+j}\right)^{\left(1-\mu_{u}\right)}\right]^{1-\varepsilon_{u}}\right),
$$

subject to the sequence of constraints

$$
\begin{gathered}
C_{u t}+\sum_{s=1}^{2} I_{u s t}\left(1+\theta\left(\frac{I_{u s t}}{K_{u s t}}\right)\right)=w_{u t} N_{u t}+\sum_{s=1}^{2}\left(r_{u s t}+\delta\right) K_{u s t}, \forall t \\
K_{u s t+1}=(1-\delta) K_{u s t}+I_{u s t}, \quad \forall t .
\end{gathered}
$$


where $I_{u s t}$ is investment in sector $s$. We restrict the rate of depreciation parameter $\delta$ to be the same across countries and sectors. The total time endowment per period is normalized to equal one. Investment is subject to convex (quadratic) costs of adjustment which depend on the ratio of gross investment to the capital stock in each sector. We restrict the cost of adjustment parameter $\theta$ to be the same in all sectors and countries. It is well known that in multi-country models without adjustment costs or time-to-build, investment volatility is much too volatile. ${ }^{7}$

\subsection{Social Planning Problem}

The social planner maximizes a weighted sum of the utilities of the representative agents of each country. If the joint stochastic process determining the model's forcing variables (the technology levels in the production functions) is stationary, the social planner's problem can be expressed as a stationary discounted dynamic programming problem. The social planner's value function is given by

$$
\begin{gathered}
V\left(\left\{z_{u j t}\right\},\left\{K_{u j t}\right\}\right)= \\
\max _{D} E\left\{\sum_{u=1}^{2} \pi_{u} u\left(C_{u t}, 1-N_{u t}\right)+E V\left(\left\{z_{u j, t+1}\right\},\left\{K_{u j, t+1}\right\}\right)\right\},
\end{gathered}
$$

where $\left\{z_{u j t}\right\}$ and $\left\{K_{u j t}\right\}$ are vectors whose elements are respectively all the exogenous productivity shocks and the capital stocks in all countries and sectors. The first summation inside the maximand is the one-period return function of the social planner. The utility of the representative agent in country $u$ is weighted by the population of country $u$, so that all agents in the model are treated equally by the social planner. If the steady-state levels of the $z_{u j}$ are the same across countries, this will ensure that each country's trade balance is zero in the steady state. $E$ denotes the mathematical expectations operator conditional on information available at time $t$, and $D$ is the vector of the social planner's control variables, which we define below. The problem is subject to the laws of motion of the capital stocks given in equation (12), and to the joint

\footnotetext{
${ }^{7}$ See Ambler and Cardia (1995) or BKK (1995).
} 
stochastic process determining the evolution of technology. Using various substitutions, $C_{u t}$ can be written as

$$
\begin{gathered}
C_{u t}=\psi_{u}\left(\phi_{u 1}\left(X_{1 s u t}, X_{2 s u t}\right)-\sum_{m=1}^{2} M_{p m 1 t}, \ldots,\right. \\
\left.\phi_{u s}\left(X_{1 s u t}, X_{2 s u t}\right)-\sum_{m=1}^{2} M_{p m s t}\right)-\sum_{s=1}^{2} I_{u s t}\left(1+\theta \frac{I_{u s t}}{K_{u s t}}\right),
\end{gathered}
$$

and where, using equations (1) and (4), we replace $X_{p s 2 t}, \forall p, \forall s$ with

$$
X_{p s 2 t}=\frac{\pi_{1}}{\pi_{2}} z_{p s t} N_{p s t}^{\alpha_{s}} K_{p s t}^{\gamma_{s}} \prod_{m=1}^{2} M_{p s m t}^{\zeta_{s m}}-\frac{\pi_{1}}{\pi_{2}} X_{p s 1 t} .
$$

With all these substitutions, it can readily be seen that the social planner's choice variables are

$$
D=\left\{I_{t}, N_{t}, M_{t}, X_{t}\right\},
$$

with

$$
\begin{gathered}
I=\left\{I_{u s t}\right\}, \quad \forall u, \forall s, \\
N=\left\{N_{u s t}\right\}, \quad \forall u, \forall s, \\
M=\left\{M_{p s m t}\right\}, \quad \forall p, \forall s, \forall m, \\
X=\left\{X_{p s 1 t}\right\}, \quad \forall p, \forall s .
\end{gathered}
$$

We use the methodology first developed by Kydland and Prescott (1982) and described in detail by Hansen and Prescott (1995) in order to simulate the model numerically. After the model is calibrated, we solve numerically for its deterministic steady state. Then, we use a quadratic approximation of the oneperiod return function in the neighborhood of the deterministic steady state, which implies that the value function is also a quadratic form, which can be found using simple iterative methods. 


\section{Calibration}

\subsection{Steady State}

Since many of the parameter values will be chosen to pin down long-run averages of variables in the model, it is convenient to analyze the steady state of the model in some detail at this stage. The steady state can be found by solving simultaneously for a certain number of static and dynamic efficiency conditions as well as market clearing conditions. The efficiency conditions can be found by considering explicitly the utility and profit maximization problems of households and firms; we abstract from these problems when we solve the model as a social planning problem.

We choose units so that the relative prices $P_{p s t}$ are all equal to one in the steady state. Then, the first order conditions for profit maximization by firms imply

$$
\begin{gathered}
\alpha_{s}=\frac{w N_{p s}}{Y_{p s}}, \\
\gamma_{s}=\frac{\left(r_{p s}+\delta\right) K_{p s}}{Y_{p s}}, \\
\zeta_{s m}=\frac{M_{p s m}}{Y_{p s}} .
\end{gathered}
$$

Given information on costs shares of labor, capital, and intermediate inputs, which is available from national accounts and input-output tables, these conditions can be used to pin down the parameters of the production functions.

We restrict the weights $\omega_{p s u}$ so that the relative prices $V_{p s t}$ are also equal to one in the steady state. The first order conditions for profit maximization by import brokers imply

$$
\omega_{p s u}=\omega_{1 s u} X_{p s u}^{\rho_{u s}} X_{1 s u}^{-\rho_{u s}}
$$

Imposing a zero profit condition then leads to the following expressions for the $\omega_{p s u}$ :

$$
\omega_{p s u}=\left(\frac{X_{p s u}}{\sum_{p=1} X_{p s u}}\right)^{\rho_{u s}} \text {. }
$$


Given information on import shares by sector and given the elasticity of substitution parameters $\rho_{u s}$, we can pin down the values of the $\omega_{p s u}$.

Solving for the first order conditions for profit maximization by domestic brokers and following a line of reasoning similar to that for the import brokers leads to the following expressions for the $\varpi_{u s}$ :

$$
\varpi_{u s}=\left(\frac{Q_{u s}}{\sum_{s=1}^{S} Q_{u s}}\right)^{\lambda_{u}} .
$$

From the first order conditions for consumption and hours it follows that

$$
\frac{1-\mu_{u}}{\mu_{u}}=\alpha_{s} \frac{\left(1-N_{u}\right)}{N_{u s}} \frac{Y_{u s}}{C_{u s}}, \quad \forall s
$$

By restricting the number of hours worked in the steady state and the steady-state ratio of consumption to output, this pins down the $\mu_{i}$ parameters. The dynamic efficiency conditions for the allocation of capital imply

$$
r_{u s}=r=\frac{1}{\beta}-1
$$

where the $r_{u s}$ are the rental rates of capital in country $u$ and sector $s$. We can use this dynamic efficiency condition either to solve for the subjective discount rate given the real rental rate of capital, or vice versa.

\subsection{Base-Case Parameter Values}

The parameter values used for the base-case simulations are summarized in Table 1 below. The model is calibrated to quarterly data. In order to isolate the role of sectoral shocks and intermediate goods in the international transmission of the business cycle from other factors, we impose symmetry across the two countries and sectors so that

$$
\begin{gathered}
\rho_{u s}=\rho, \quad \forall u, \forall s, \\
\lambda_{u}=\lambda, \quad u=1,2,
\end{gathered}
$$




$$
\begin{aligned}
& \mu_{u}=\mu, \quad u=1,2, \\
& \varepsilon_{u}=\varepsilon, \quad u=1,2 .
\end{aligned}
$$

We normalize the population in each country to equal one. The parameter values calibrated from long run averages in the data are as follows.

- The weights on capital and labor in the production functions are standard. They ensure that labor's and capital's share of national income match the average values in the data.

- We set the total weight on intermediate goods in the production functions to 0.5 , which matches the average value from U.S. input-output tables.

- We choose the value of $\mu$ so that households allocate one third of their discretionary time per period to leisure.

- The average share of imported versus domestically produced goods from the U.S. input-output tables gives us

$$
\begin{aligned}
& X_{1 s 1}=X_{2 s 2}=0.85, s=1,2 \\
& X_{1 s 2}=X_{2 s 1}=0.15, s=1,2 .
\end{aligned}
$$

The total production of each type of good is normalized to equal one by a suitable choice of the steadystate levels of the $z_{p s t}$. Import shares reflect a strong degree of home preference, with $85 \%$ of domestic production of all types of goods consumed domestically.

The remaining parameters of the model are the depreciation rate of capital $\delta$, the adjustment cost parameter $\theta$, the elasticity of substitution parameters $\rho_{u s}$ and $\lambda_{u}$, the preference parameters $\varepsilon_{u}$, and the parameters of the multivariate stochastic process governing the evolution of the productivity variables $z_{u s}$. 
We set standard values from the literature and, whenever possible, we used values equal to those in BKK (1995) in order to facilitate comparison with their results. The values were chosen as follows.

- We set a standard value for the depreciation rate $(\delta=0.025)$.

- We set the adjustment cost parameter so that the relative volatility of aggregate investment matches the data $(\theta=1.00)$ for the benchmark model economy. Cardia (1991) and Mendoza (1991) use a similar approach.

- We set the value of the substitution parameters in the Armington aggregators $(\rho)$ to give an elasticity of 1.5 on the basis of previous studies in the trade literature, notably Stern and Schumacher (1976), Whalley (1985) and Shiells and Reinert (1993).

- We set the value of the substitution parameters in the final goods aggregators $(\lambda)$ to give an elasticity of 0.9 based on Whalley (1985).

- We set the value of $\varepsilon_{u}$ based on standard values in the literature. BKK (1995) use the same value.

- We set the average interest rate to $4 \%$ per year, which implies a value of $\beta$ equal to 0.99 .

- The stochastic process generating the $z_{u s}$ 's was calibrated by estimating a first-order vector autoregression (VAR), using data for manufacturing and non-manufacturing output in the U.S. and a group of European countries. ${ }^{8}$ The estimation results give:

$$
\begin{gathered}
{\left[\begin{array}{l}
z_{11, t+1} \\
z_{12, t+1} \\
z_{21, t+1} \\
z_{22, t+1}
\end{array}\right]=} \\
{\left[\begin{array}{cccc}
0.910 & -0.020 & -0.034 & 0.076 \\
0.006 & 0.878 & 0.140 & -0.047 \\
0.110 & 0.076 & 0.736 & 0.100 \\
0.375 & 0.105 & 0.183 & 0.618
\end{array}\right]\left[\begin{array}{l}
z_{11 t} \\
z_{12 t} \\
z_{21 t} \\
z_{22 t}
\end{array}\right]+\left[\begin{array}{l}
\xi_{11 t+1} \\
\xi_{12 t+1} \\
\xi_{21 t+1} \\
\xi_{22 t+1}
\end{array}\right] .}
\end{gathered}
$$

\footnotetext{
${ }^{8}$ Complete details concerning the data are available on request.
} 
The correlation matrix of the innovations is given by:

$\left[\begin{array}{llll}1.000 & 0.174 & 0.084 & 0.204 \\ 0.174 & 1.000 & 0.230 & 0.081 \\ 0.084 & 0.230 & 1.000 & 0.189 \\ 0.204 & 0.081 & 0.189 & 1.000\end{array}\right]$,

with percentage standard deviations equal to $0.706,1.584,0.634$ and 1.425 .

\subsection{GDP, Trade Balance and the Terms of Trade}

We can define the following aggregate variables, which are necessary for calculating some of our simulation results.

- Country $u$ 's GDP is given by the following expression:

$$
G D P_{u t}=\pi_{u} \sum_{s=1}^{S} Y_{p s t} \frac{\partial \phi_{p s}}{\partial X_{p s u t}} \frac{\partial \psi_{s}}{\partial Q_{u s t}}-p i_{u} \sum_{s=1}^{S} \sum_{m=1}^{S} M_{u s m t} \frac{\partial \psi_{u}}{\partial Q_{u s t}} .
$$

GDP is calculated by summing up the value added in each sector of the economy, measured in units of aggregate consumption. Sectoral output $Y_{p s t}$ is multiplied by the relative price $\frac{\partial \phi_{p s}}{\partial X_{p s u}}$ to obtain the value of output in sector $s$ in terms of the composite home/foreign good $u$. Then, we multiply by the relative price $\frac{\partial \psi_{u}}{\partial Q_{u s t}}$ which gives the marginal contribution of composite good $u$ to aggregate consumption. We subtract the value (in terms of aggregate consumption) of the intermediate inputs used in all sectors of the economy. The numeraire good is taken to be aggregate consumption.

- The trade balance of country $u$ is given by:

$$
\begin{gathered}
B_{u t}= \\
\sum_{p=1}^{H} \pi_{u} \sum_{s=1}^{S} X_{p s u t} \frac{\partial \phi_{p s}}{\partial X_{p s u t}} \frac{\partial \psi_{u}}{\partial Q_{u s t}}-\sum_{p=1}^{H} \pi_{i} \sum_{s=1}^{S} X_{p s u t} \frac{\partial \phi_{p s}}{\partial X_{p s u t}} \frac{\partial \psi_{u}}{\partial Q_{u s t}} .
\end{gathered}
$$

Once again, the values of exports and imports are measured in terms of units of aggregate consumption

of country $u$. The exports of each sector to all countries are multiplied by $\frac{\partial \phi_{p s}}{\partial X_{p s u}}$ to obtain their value 
in terms of the composite home/foreign good $u$, and then by $\frac{\partial \psi_{u}}{\partial Q_{u s}}$ to obtain their value in units of aggregate consumption. Imports from country $p$ of good $s, X_{p s u t}$, are multiplied by $\frac{\partial \phi_{p s}}{\partial X_{p s u}}$ to obtain their value when used in country $u$ in terms of the composite good $s$ and by $\frac{\partial \psi_{u}}{\partial Q_{u s}}$ to convert to units of domestic aggregate consumption. The per-capita trade balance can be obtained by dividing the above expression by $\pi_{u}$.

- The sectoral terms of trade for sector $s$ and between countries $u$

$$
T O T_{u l s t} \equiv\left(\frac{\partial \phi_{u s}}{\partial X_{u s u t}}\right)^{-1}\left(\frac{\partial \phi_{u s}}{\partial X_{l s u t}}\right)
$$

- We calculate the real exchange rate between countries $u$ and $l$ as the ratio of two Laspeyres indices of the price of output in the two countries:

$$
R E R_{t}=\frac{\left(\sum_{s} P_{u s t} X_{u s}\right) /\left(\sum_{s} P_{u s} X_{u s}\right)}{\left(\sum_{s} P_{l s t} X_{l s}\right) /\left(\sum_{s} P_{l s} X_{l s}\right)},
$$

where the $P_{. s t}$ are the relative prices of the different sectoral outputs, the $P_{. s}$ are the relative prices in the steady state, and the $X_{. j}$ are the sectoral outputs in the steady state. For country $j$, the real exchange rate measures the relative price of imports to exports, as is standard in the international finance literature. ${ }^{9}$

\section{Results}

\subsection{Base Case}

The main results for the base-case scenario are presented in Tables 2 and 3. The results are based on 200 replications of histories of 100 quarters in length. We generated histories of 165 observations and truncated the first 65 observations so that the results do not depend on initial conditions. ${ }^{10}$ The figures in parentheses

\footnotetext{
${ }^{9} \mathrm{BKK}$ refer to this measure as the terms of trade.

${ }^{10}$ The state variables of the model are initialized at their steady-state levels.
} 
associated with each moment statistic indicate the standard deviations of the calculated statistic across replications. They give a rough indication of the statistical significance of the statistics. We report standard deviations only for the base case scenario in order to conserve space - the standard deviations are very similar across model specifications and calibrations. For purposes of comparison, we also report the predicted moments from the BKK benchmark model in the third row of each table.

The relative standard deviations of variables and the domestic correlations of output with its components and with hours worked are mostly similar to those generated by closed-economy real business cycle models. However, the relative volatility of consumption is somewhat too low, which is common in multi-country models due to the added risk sharing opportunities that such models embody. In addition, the model generates a negative correlation between output and net exports (the trade balance), which is consistent with the data. As is common in previous multi-country business cycle models, the volatility of the real exchange rate is counterfactually low. It is in fact significantly lower than the prediction of the BKK benchmark two-good model.

The cross-country correlations are significantly different than those predicted by the BKK benchmark model. There is a significant amount of positive transmission of the business cycle, with a cross correlation of output levels equal to 0.30 in our base case. This cross correlation is higher than the average in the Zimmermann (1995) data set but is within one standard deviation of this number. The model resolves only one part of the quantity anomaly, since it still predicts a cross-country correlation of consumption levels that is significantly higher than the cross correlation of output. This is not surprising. Our specification of preferences is similar to that of the BKK benchmark, and there is nothing in our model which inhibits risk sharing by agents in different countries. While the cross-correlations of investment and of employment predicted by the model are negative, both values are within one standard deviation of zero, and both values are significantly less negative than in the BKK benchmark. Furthermore, the predicted values are within 
two standard deviations of the cross-country averages from the Zimmermann (1995) data set. We conclude that the model's predictions concerning the international transmission of the business cycle are broadly compatible with the data in all respects except the cross- country correlation of consumption. ${ }^{11}$

\subsection{Sensitivity Analysis}

Sensitivity analysis allows us to check on the robustness of the results and to pinpoint which aspects of our model are responsible for generating a positive international transmission of the business cycle. We can also assess the relative impact of multiple sectors compared to other changes in specification on the international transmission of the business cycle.

The elasticity of substitution parameters in the Armington and final goods aggregators have only minor effects on the results. Sensitivity results with respect to the $\lambda_{u}$ parameters in the final goods are not shown. Results are shown in Tables 2 and 3 for two different scenarios with a low elasticity of substitution between domestic and foreign goods in the Armington aggregators. Reducing the elasticity of substitution by increasing $\rho$ makes the international transmission of the business cycle more positive, but the effect is not always monotonic. The cross-country correlation of output increases to 0.42 as the value of $\rho$ increases to $1 / 0.15$. The cross-country correlation of consumption first increases to 0.83 as the value of $\rho$ increases to $1 / 0.5$, and then decreases to 0.66 with $\rho=1 / .15$. The effect on the cross-country correlation of investment is similar. It increases to 0.03 as the value of $\rho$ goes from $1 / 1.5$ to $1 / 0.5$, and then decreases again to -0.21 with $\rho=1 / 0.15$. The effect on the cross correlation of investment is not significant, given the large standard error associated with this statistic. The reasons for a more positive international transmission of the cycle as $\rho$ increases are intuitive. A positive shock to technology in one sector increases the demand for the outputs of all other sectors in all countries, both as intermediate inputs in the sector affected by

\footnotetext{
${ }^{11}$ Our results are compatible with the existence of a J-curve, as in Backus, Kehoe and Kydland (1994). The contemporaneous correlation between the real exchange rate and net exports is negative, but is positive between net exports and the first eight lags of the exchange rate. The highest correlation is between net exports and the third lag of the real exchange rate.
} 
the favorable technology shock and due to a positive wealth effect on final demand. As goods in different countries become less substitutable, the demand shift has a greater final impact on the quantities of these goods that are produced.

Our results show that the size of adjustment costs has important effects on the international transmission of the cycle. The predicted volatilities of aggregates are not strongly affected by the size of the adjustment cost parameter $\theta$, except for the volatilities of investment and the trade balance, which both decrease as adjustment costs increase. However, the cross-country correlations are quite sensitive. As $\theta$ increases, the cross-country correlations of output, employment and investment increase (the effect on the latter is not monotonic), and the cross-country correlation of consumption decreases slightly. These results are once again intuitive. As adjustment costs increase, it becomes less easy to shift factors of production towards the sectors and countries where they are most productive. The cross correlations are increasingly dominated by the positive spillover effect that a positive shock in one sector has on the demand for goods of other sectors and countries.

The two parameters with the strongest impact on the international transmission of the cycle are the capital depreciation rate $\delta$ and the degree of home preference captured by the share of imported versus domestically produced goods. As the depreciation rate increases, and as home preference becomes less pronounced, the international transmission of the cycle becomes more positive. With a depreciation rate of $100 \%,{ }^{12}$ the cross correlation of output levels is almost as high as that of consumption, and the cross correlations of both investment and employment become strongly positive. The intuition for this result is clear. With low depreciation, a negative shock to one sector reduces investment without substantially reducing the capital stock. The marginal productivity of capital remains fairly stable. With high depreciation, lower investment translates directly into a lower capital stock, which raises its marginal productivity drastically.

\footnotetext{
${ }^{12}$ This case corresponds to the closed-economy model analyzed by Long and Plosser (1983). They find that in a model with $100 \%$ depreciation, uncorrelated sectoral productivity shocks can lead to positive comovements in sectoral outputs.
} 
This discourages negative comovements of investment across sectors and countries in response to productivity differentials.

With no home preference (half of the total production of each type of good is exported), the results are quite dramatic. The cross-country correlation of output levels increases to 0.97 , and the cross-country correlations of both investment and employment increase to counterfactually high levels. The cross-country correlation of consumption levels is not significantly different from one. The latter result is intuitive. With no home preference, the consumption preferences of the home and foreign agent are identical, and with risk sharing the consumption levels of the two agents are almost perfectly correlated. It is only because utility also depends on leisure, which is a nontradable good, that the correlation is less than perfect. The high correlation of investment seems quite surprising. To explain this result, we examined the impulse responses of domestic and foreign investment to a positive domestic productivity shock. Domestic investment increases substantially in response to a positive productivity shock. The increase is persistent, with a monotonic decay back to its steady state level. With no home preference, foreign investment also increases in response to a domestic productivity shock. The size of the increase is small, but it is also persistent, with the same monotonic decrease to the steady state. It is the qualitative similarity in the impulse responses which leads, despite the difference in the size of the responses, to the high cross correlation.

In order to investigate the sensitivity of international transmission to the specification of production technology, we tried a series of simulations in which we replace the Cobb-Douglas production functions with nested CES functions, with an elasticity of substitution between labor and capital equal to 1.0 and an elasticity of substitution between primary and intermediate inputs equal to $0.5 .^{13}$ The results for cross correlations are similar to those in the base case, except for employment. With a lower elasticity of substitution between primary and intermediate inputs, the positive cross-country correlation of output levels is accompanied by

\footnotetext{
${ }^{13}$ This calibration is inspired by the work of Whalley (1985), who assumes a Leontief-style production function, with fixed input coefficients on an aggregate of primary inputs (with a unit elasticity of substitution between capital and labor) and intermediate goods.
} 
a positive cross correlation of employment, since it is less easy to substitute other factors of production for labor.

We also report simulation results for a scenario in which we remove the spillover effects in the international transmission of technology shocks. We do so by setting the off-diagonal elements of the matrix of autoregressive coefficients of our estimated VAR to zero. We set the diagonal elements equal to their estimated values. Sectoral Solow residuals can still be correlated, by this is now due solely to the contemporaneous correlations of the innovations. Relative volatilities are not generally affected, as shown in Table 2 , with the exceptions of the trade balance which becomes more volatile. The contemporaneous correlation of the real exchange rate with output becomes more positive. Table 3 shows that the international transmission of the cycle actually becomes more positive. The cross correlation of output levels is not strongly affected, but the cross country correlations of investment and employment both become positive. In addition, removing spillover effects reduces the predicted cross correlation of consumption levels. These results show that modelling technology spillovers using an estimated VAR may actually lead the model to underpredict the international transmission of the cycle.

The specification of our model differs from that of the BKK benchmark primarily because it incorporates both intermediate goods and multiple sectors. We simulated versions of the model without intermediate goods and with only one sector in each country (both with and without intermediate goods) in order to judge the relative contributions of these changes to our results. The results show that the introduction of intermediate goods does not have strong effects on the predictions of the model. The cross-country correlations are very similar in both versions of the two-sector model (with and without intermediate goods). The cross-country correlations are also very similar in the one sector model with intermediates and without intermediates. ${ }^{14}$ However, going from a one-sector specification to a two-sector specification leads to a more

\footnotetext{
${ }^{14}$ Rotemberg and Woodford (1995) show that models in models with constant returns to scale in production, perfect competition, and no capital adjustment costs, production functions for gross output can be replaced with value added production
} 
positive international transmission of the cycle, especially for the cross-country correlations of investment and employment. This result can be explained by examining the relative impact of productivity shocks in the one-sector and two-sector models. In the one-sector model, the country that benefits from a positive productivity shock draws productive resources from abroad. In the two-sector model, a positive productivity shock in one sector leads to a flow of resources both from abroad and from other sectors within the same country. Because cross-sectoral comovements within countries are less positive, cross-country comovements of output and other aggregates are more positive.

The one-sector model without intermediate goods is the specification of our model which is closest to the BKK benchmark. The two differ only in how the adjustment of capital is modelled. The BKK benchmark uses time-to-build, while our specification imposes convex adjustment costs that depend on the rate of gross investment. With convex adjustment costs, the capital flows induced by productivity differentials are dampened because of the costs of installing new capital. With time-to-build, investment projects do not come on line immediately. However, if productivity differentials are persistent enough, they can lead to capital flows that are more massive than in the presence of adjustment costs. Consequently, our single-sector model generates a higher cross-country correlation of output levels and cross correlations of investment and employment that are less negative than the BKK benchmark.

\section{Conclusions}

We have developed a two-country multi-sector model of the business cycle. Our results show that such a model is capable of generating a positive international transmission of the business cycle, with cross-country correlations of output, employment, and investment that are broadly compatible with the data for a large group of industrialized countries. Our sensitivity analysis shows that the international transmission of the

functions with no loss in generality. The (relatively small) impact of intermediate goods on the predictions of our model can be explained by the presence of adjustment costs. 
business cycle is quite sensitive to a number of key parameters of the model. International transmission becomes more consistent with the data when domestic and foreign goods become less substitutable, when capital adjustment costs are higher, when depreciation costs are higher and when there is a lower degree of home preference. The cross-country correlation of employment is also sensitive to the elasticity of substitution between inputs in the production functions.

The change in model specification with respect to the BKK benchmark that has the the strongest effects on the international transmission of the business cycle is the introduction of multiple sectors. The presence of intermediate inputs in production is much less important. The two-sector model leads to similar predictions concerning cross-country correlations, as the total weight on intermediate goods in the production functions varies between 0.5 and zero. The predictions of the one-sector version of the model for cross-country correlations are also very similar with and without intermediate goods in the production functions. Using convex adjustment costs rather than time-to-build also makes the international transmission of the business cycle more positive, with a particularly strong effect on the cross correlations of investment and employment.

The cross-country correlation of consumption predicted by our model remains very high. We conjecture that a satisfactory explanation of all aspects of the quantity anomaly will necessitate using models that combine multiple sectors with other features such as market imperfections that limit risk sharing. Other papers (for example Kehoe and Perri, 1996) show that reduced risk sharing can have important effects on the cross-country correlation of consumption, in addition to affecting the cross-country correlations of other variables such as output and investment. Our results show that it is possible to build a model of the international business cycle that explains many of the features of the quantity anomaly, without imposing restrictions on risk sharing or the flows of capital across national borders.

\section{References}

Ambler, Steve and Emanuela Cardia (1995), "Les modèles réels de la transmission internationale du cycle 
économique", Actualité économique: revue d'analyse économique $71,193-217$

Armington, Paul (1969), "A Theory of Demand for Products Distinguished by Place of Production", International Monetary Fund Staff Papers 27, 488-526

Arvanitis, Athanasios and Anne Mikkola (1996), "Asset-Market Structure and International Trade Dynamics", American Economic Review Papers and Proceedings 86, 67-70

Backus, David, Patrick Kehoe and Finn Kydland (1994), "Dynamics of the Trade Balance and the Terms of Trade: The J-Curve?", American Economic Review 84, 84-103

Backus, David, Patrick Kehoe and Finn Kydland (1995), "International Business Cycles: Theory and Evidence", in Thomas F. Cooley, ed., Frontiers of Business Cycle Research (Princeton, NJ, Princeton University Press) 331-356

Baxter, Marianne (1995), "International Trade and Business Cycles", in Gene M. Grossman and Kenneth Rogoff, eds., Handbook of International Economics v.3 (Amsterdam, North Holland) 1801-1864

Baxter, Marianne and Mario Crucini (1995), "Business Cycles and the Asset Structure of Foreign Trade", International Economic Review 36, 821-854

Canova, Fabio and Angel Ubide (1998), "Household Production and International Business Cycles", Journal of Economic Dynamics and Control 22, 545-572

Cardia, Emanuela (1991), "The Dynamics of a Small Open Economy in Response to Monetary, Fiscal and Productivity Shocks", Journal of Monetary Economics 28, 411-34

Costello, Donna and Jack Praschnik (1993), "Intermediate Goods and the Transmission of International Business Cycles", mimeo, University of Western Ontario

Devereux, Michael, Allan Gregory and Gregor Smith (1992), "Realistic Cross-Country Consumption Correlations in a Two-Country, Equilibrium Business Cycle Model", Journal of International Money and Finance 11, 3-16

Hansen, Gary and Edward Prescott (1995), "Recursive Methods for Computing Equilibria of Business Cycle Models" in Thomas F. Cooley, ed., Frontiers of Business Cycle Research (Princeton, NJ, Princeton University Press) 39-64

Head, Allen (1997), "Aggregate Fluctuations with National and International Returns to Scale", mimeo, Queen's University

Heathcote, Jonathan and Fabrizio Perri (1997), "Financial Autarky and International Business Cycles", mimeo, University of Pennsylvania

Hornstein, Andreas and Jack Praschnik (1997), "Intermediate Inputs and Sectoral Comovement in the Business Cycle", Journal of Monetary Economics 40, 573-595

Horvath, Michael T. K. (1998), "Cyclicality and Sectoral Linkages: Aggregate Fluctuations from Independent Sectoral Shocks", Review of Economic Dynamics 1, 781-808

Kehoe, Patrick and Roberto Perri (1996), "International Business Cycles with Endogenous Market Incompleteness", mimeo, Research Department, Federal Reserve Bank of Minneapolis

Kollmann, Robert (1992), "Consumption, Real Exchange Rates, and the Structure of International Asset Markets", mimeo, Université de Montréal

Kouparitsas, Michael (1996), "North-South Financial Integration and Business Cycles", working paper 96-10, Federal Reserve Bank of Chicago

Kydland, Finn and Edward Prescott (1982), "Time to Build and Aggregate Fluctuations", Econometrica $50,1345-1370$

Long, John and Charles I. Plosser (1983), "Real Business Cycles", Journal of Political Economy 91, 39-69

Mendoza, Enrique (1991), "Real Business Cycles in a Small Open Economy", American Economic Review $81,798-818$ 
Park, Hyung-soo (1998), "International Business Cycle and Transmission Mechanism: Resolving Puzzles and Source of International Comovement", mimeo, University of California at Los Angeles

Ricketts, Nicholas and Thomas McCurdy (1995), "An International Economy with Country-Specific Money and Productivity Growth Processes", Canadian Journal of Economics 28, S141-S162

Rotemberg, Julio and Michael Woodford (1995), "Dynamic General Equilibrium Models with Imperfectly Competitive Product Markets", in Thomas F. Cooley, ed., Frontiers of Business Cycle Research (Princeton, NJ, Princeton University Press) 331-356

Shiells, C.R. and K.A. Reinert (1993), "Armington Models and Terms-of-Trade Effects: Some Econometric Evidence for North America", Canadian Journal of Economics 26, 299-316

Stern, R.M. and B. Schumacher (1976), Price Elasticities in International Trade: An Annotated Bibliography (New York, NY, Macmillan)

Stockman, Alan and Linda Tesar (1995), "Tastes and Technology in a Two-Country Model of the Business Cycle: Explaining International Comovements", American Economic Review 85, 168-185

Whalley, John (1985), Trade Liberalization among Major World Trading Areas (Cambridge, MA, MIT Press)

Zimmermann, Christian (1995), "International Trade over the Business Cycle: Stylized Facts and Remaining Puzzles", cahier de recherche 37, Centre de recherche sur l'emploi et les fluctuations économiques, Université du Québec à Montréal 
Table 1

Benchmark Parameters Values

\begin{tabular}{lll}
\hline \hline & & \\
Preferences & $\beta$ & 0.99 \\
Discount Factor & $\mu$ & 0.34 \\
Consumption Share & $\varepsilon$ & 2.00 \\
Curvature Parameter & & \\
Technology & $\alpha$ & 0.32 \\
Labor Share & $\gamma$ & 0.18 \\
Capital Share & $\zeta$ & 0.25 \\
Intermediate Goods Share & $\delta$ & 0.025 \\
Depreciation rate & $\theta$ & 1.00 \\
Investment Adjustment Costs & $N$ & 0.33 \\
Steady State Hours Worked & & \\
Armington Aggregator (Imports) & $1 / \rho$ & 1.50 \\
Elasticity of Substitution & & 0.85 \\
$X_{1 s 1} / Y_{1 s}=X_{2 s 2} / Y_{2 s}, s=1,2$ & & 0.15 \\
$X_{1 s 2} / Y_{1 s}=X_{2 s 1} / Y_{2 s}, s=1,2$ & & \\
CES Aggregator (Domestic Brokers) & & \\
Elasticity of Substitution & $1 / \lambda$ & 0.90 \\
& & \\
\hline \hline
\end{tabular}


Table 2

Simulation Results

\begin{tabular}{|c|c|c|c|c|c|c|c|c|c|c|c|}
\hline & \multicolumn{2}{|c|}{ St. Dev. (\%) } & \multicolumn{4}{|c|}{ " Relative St. Dev. } & \multicolumn{5}{|c|}{ "Correlation with Output } \\
\hline & $\mathbf{Y}$ & TB & C & $\mathbf{I}$ & $\mathbf{N}$ & $\mathbf{e}$ & $\mathbf{C}$ & $\mathbf{I}$ & $\mathbf{N}$ & TB & $\mathbf{e}$ \\
\hline U.S. Data ${ }^{a}$ & 1.92 & 0.52 & 0.75 & 3.27 & 0.61 & 3.68 & 0.82 & 0.94 & 0.88 & -0.37 & -0.20 \\
\hline Cross-Country Average ${ }^{b}$ & 1.62 & 1.05 & 0.30 & 2.97 & 0.71 & 2.31 & 0.69 & 0.80 & 0.57 & -0.32 & -0.03 \\
\hline BKK Benchmark $^{a}$ & 1.38 & 0.30 & 0.47 & 3.48 & 0.42 & $0.48^{f}$ & 0.88 & 0.93 & 0.94 & -0.64 & 0.49 \\
\hline Base Case $^{c}$ & $\begin{array}{c}2.64 \\
(0.27)\end{array}$ & $\begin{array}{c}0.20 \\
(0.02)\end{array}$ & $\begin{array}{c}0.52 \\
(0.04)\end{array}$ & $\begin{array}{c}2.84 \\
(0.17)\end{array}$ & $\begin{array}{c}0.35 \\
(0.02)\end{array}$ & $\begin{array}{c}0.06 \\
(0.00)\end{array}$ & $\begin{array}{c}0.92 \\
(0.22)\end{array}$ & $\begin{array}{c}0.96 \\
(0.01)\end{array}$ & $\begin{array}{c}0.93 \\
(0.02)\end{array}$ & $\begin{array}{c}-0.48 \\
(0.13)\end{array}$ & $\begin{array}{c}0.47 \\
(0.12)\end{array}$ \\
\hline \multicolumn{12}{|l|}{ Sensitivity Analysis ${ }^{d}$} \\
\hline$\theta=0$ & 2.89 & 0.50 & 0.45 & 3.46 & 0.42 & 0.03 & 0.87 & 0.95 & 0.95 & -0.57 & 0.28 \\
\hline$\theta=2$ & 2.64 & 0.19 & 0.50 & 2.55 & 0.36 & 0.07 & 0.95 & 0.97 & 0.97 & -0.03 & 0.48 \\
\hline$\rho=1 / 0.15$ & 2.88 & 0.52 & 0.48 & 3.18 & 0.38 & 0.07 & 0.97 & 0.95 & 0.98 & -0.60 & 0.14 \\
\hline$\rho=1 / 0.5$ & 2.73 & 0.41 & 0.52 & 2.37 & 0.40 & 0.03 & 0.87 & 0.94 & 0.90 & 0.73 & 0.70 \\
\hline$\delta=0.5$ & 2.45 & 0.58 & 0.91 & 0.94 & 0.11 & 0.13 & 0.99 & 0.98 & 0.78 & 0.40 & 0.39 \\
\hline$\delta=1$ & 2.86 & 0.69 & 0.91 & 1.01 & 0.01 & 0.01 & 0.99 & 0.96 & 0.97 & 0.36 & 0.35 \\
\hline CES Production Function ${ }^{e}$ & 2.78 & 0.29 & 0.52 & 2.86 & 0.36 & 0.07 & 0.93 & 0.96 & 0.97 & -0.42 & 0.36 \\
\hline No Home Preference & 2.19 & 0.20 & 0.60 & 2.23 & 0.32 & 0.50 & 0.93 & 0.94 & 0.90 & 0.38 & 0.06 \\
\hline No Spillover Effects & 2.95 & 1.60 & 0.34 & 3.09 & 0.41 & 0.06 & 0.97 & 0.99 & 0.99 & -0.03 & 0.72 \\
\hline No Intermediate Goods & 1.32 & 0.12 & 0.52 & 2.80 & 0.36 & 0.14 & 0.93 & 0.96 & 0.93 & -0.49 & 0.50 \\
\hline One Sector Model & 2.76 & 0.60 & 0.52 & 4.09 & 0.38 & 0.17 & 0.90 & 0.87 & 0.93 & -0.60 & 0.46 \\
\hline One Sector w/o Intermediates & 1.36 & 0.21 & 0.55 & 2.72 & 0.37 & 0.26 & 0.94 & 0.95 & 0.94 & -0.60 & 0.59 \\
\hline One Sector $\mathbf{w} / \mathbf{o}$ Intermediates, $\theta=0^{c}$ & 1.46 & 0.34 & 0.49 & 3.41 & 0.58 & 0.18 & 0.90 & 0.92 & 0.93 & -0.63 & 0.47 \\
\hline One Sector w/o Intermediates, $\theta=2^{c}$ & 1.30 & 0.15 & 0.60 & 2.39 & 0.30 & 0.32 & 0.96 & 0.96 & 0.94 & -0.58 & 0.58 \\
\hline
\end{tabular}

\footnotetext{
a: From Backus, Kehoe and Kydland (1995).

b: From Zimmermann (1995).

c: Parameter values are described in Table 1 and in the text.

$\mathrm{d}$ : Parameter values as in base case except as noted.

e: See the text for the parameterization of the production function.

$\mathrm{f}$ : This statistic is from the two-good version of the BKK model.
} 
Table 3

Simulation Results

\begin{tabular}{|c|c|c|c|c|}
\hline & \multicolumn{4}{|c|}{ Cross-Correlations } \\
\hline & $\mathbf{Y}$ & $\mathrm{C}$ & $\mathbf{I}$ & $\mathbf{N}$ \\
\hline U.S. Data $^{a}$ & 0.66 & 0.51 & 0.53 & 0.33 \\
\hline Cross-Country Average ${ }^{b}$ & 0.24 & 0.14 & 0.16 & 0.21 \\
\hline BKK Benchmark $^{a}$ & 0.02 & 0.77 & -0.58 & -0.54 \\
\hline Base Case $^{c}$ & $\begin{array}{c}0.32 \\
(0.12)\end{array}$ & $\begin{array}{c}0.78 \\
(0.06)\end{array}$ & $\begin{array}{c}-0.12 \\
(0.13)\end{array}$ & $\begin{array}{l}-0.05 \\
(0.14)\end{array}$ \\
\hline \multicolumn{5}{|l|}{ Sensitivity Analysis ${ }^{d}$} \\
\hline$\theta=0$ & 0.24 & 0.82 & -0.31 & -0.08 \\
\hline$\theta=2$ & 0.40 & 0.74 & 0.08 & 0.25 \\
\hline$\rho=1 / 0.15$ & 0.42 & 0.66 & -0.21 & 0.19 \\
\hline$\rho=1 / 0.5$ & 0.22 & 0.83 & 0.03 & -0.26 \\
\hline$\delta=0.5$ & 0.54 & 0.77 & 0.62 & -0.54 \\
\hline$\delta=1$ & 0.63 & 0.80 & 0.78 & 0.27 \\
\hline CES Production Function ${ }^{e}$ & 0.48 & 0.84 & 0.02 & 0.53 \\
\hline No Home Preference & 0.97 & 0.99 & 0.98 & 0.90 \\
\hline No Spillover Effects & 0.32 & 0.40 & 0.15 & 0.32 \\
\hline No Intermediate Goods & 0.33 & 0.78 & -0.15 & -0.05 \\
\hline One-Sector Model & 0.22 & 0.80 & -0.63 & -0.45 \\
\hline One Sector w/o Intermediates & 0.24 & 0.75 & -0.35 & -0.40 \\
\hline One Sector w/o Intermediates, $\theta=0$ & 0.12 & 0.79 & -0.55 & -0.52 \\
\hline One Sector w/o Intermediates, $\theta=2$ & 0.29 & 0.72 & -0.20 & -0.36 \\
\hline
\end{tabular}

$a$ See notes to Table 2. The correlations are between the U.S. and Europe. $b, c, d, e \quad$ See notes to Table 2 . 
Figure 3

Production Structure of Model

Country 1

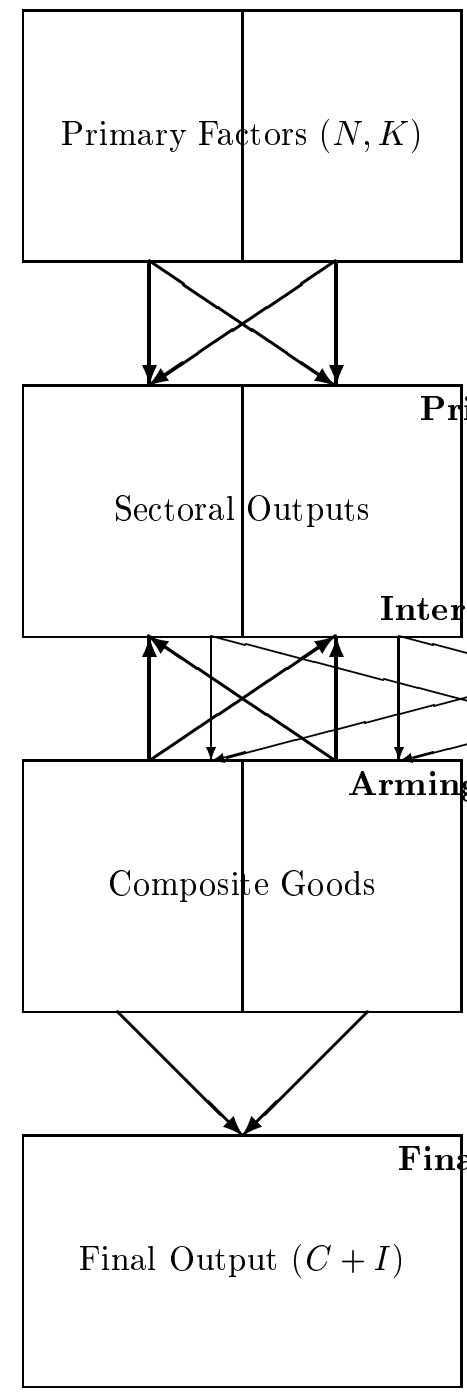

Country 2

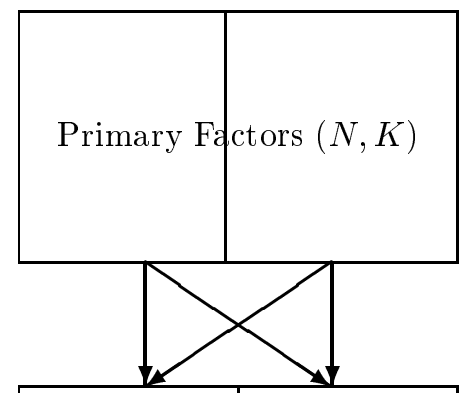

Primary Inputs

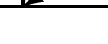

ectoral Outputs

ediate Inputs

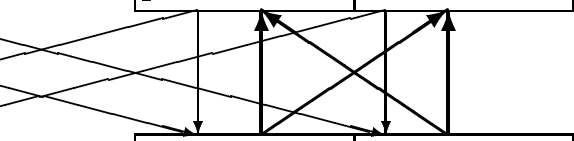

ton Aggregators

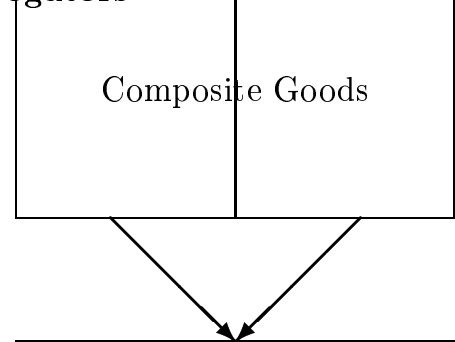

inal Aggregators

Final Output $(C+I)$ 


\section{Figure 1}

Cross Correlations

Occurrences
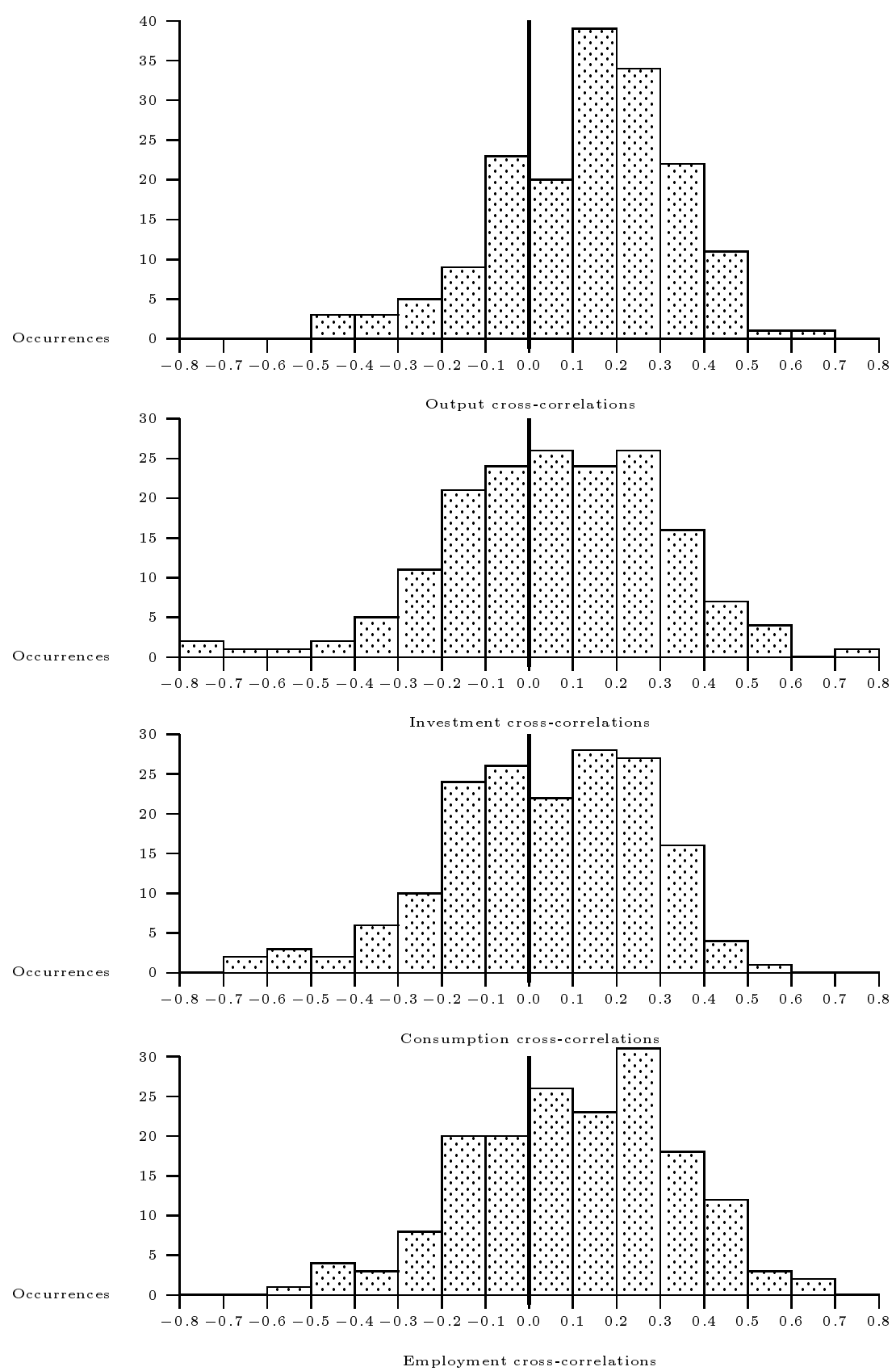
Figure 2

Trade Balance and Terms of Trade
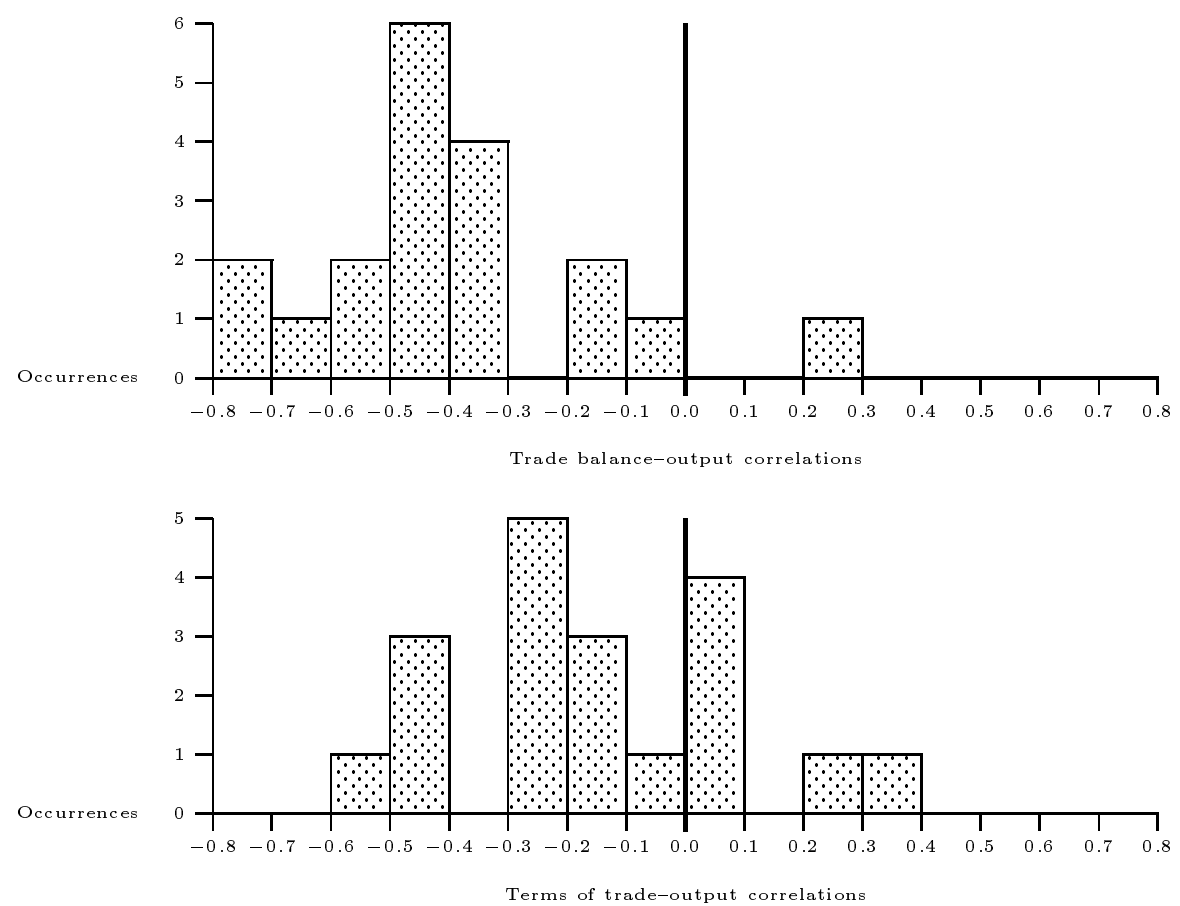